\title{
Does HIV Status Affect Utilization of Maternal Care Services among Women in India: An Analysis of NFHS 2005-2006
}

\author{
Vasudevan Jayachandran', Damodar Sahu², Subramanian Rajaram³, Bo Pedersen", \\ Arvind Pandey ${ }^{2}$ \\ ${ }^{1}$ Catholic Relief Services (CRS), Blantyre, Malawi \\ ${ }^{2}$ National Institute of Medical Statistics (NIMS-ICMR), New Delhi, India \\ ${ }^{3}$ Karnataka Health Promotion Trust (KHPT), Bangalore, India \\ ${ }^{4}$ United Nations Children's Fund (UNICEF), New York, USA \\ Email: sahud@icmr.org.in
}

Received 16 March 2015; accepted 31 May 2015; published 3 June 2015

Copyright (C) 2015 by authors and Scientific Research Publishing Inc.

This work is licensed under the Creative Commons Attribution International License (CC BY). http://creativecommons.org/licenses/by/4.0/

(c) (i) Open Access

\begin{abstract}
The objective of the study is to understand the relationship between HIV status, fertility and utilisation of maternal care services in India using the NFHS 2005-2006 data. The mean number of children ever born (a measure of fertility) is substantially higher among HIV-negative women than among the HIV-positive women ( 2.8 and 2.1 respectively). Ten-year age specific fertility rates (ASFR) were calculated, there is no noticeable difference in pattern of ASFR between HIV-positive and HIV-negative category of women observed though the ASFRs were substantially lower among the HIV-positive women. The total fertility rate (TFR) among HIV-positive women (0.84) is substantially lower at one third of the TFR among HIV-negative women (2.78). The proportion of HIV-positive pregnant women utilising ANC services is 92 percent compared to 78 percent among HIV-negative women, who have alive birth during the 5-year preceding the survey. Similarly, the proportion of HIV-positive women (67\%) delivering their babies in an institution is also much higher than among HIV-negative women $(40 \%)$. This study concludes that the effort of the government to integrate ART services with maternity care services is likely to have benefited the HIV positive mothers.
\end{abstract}

\section{Keywords}

HIV-Positive, Total Fertility Rate, Reproductive Health, NFHS

\section{Introduction}

The Millennium Development Goal 5 on improving maternal health calls for reducing maternal mortality by in-

How to cite this paper: Jayachandran, V., Sahu, D., Rajaram, S., Pedersen, B. and Pandey, A. (2015) Does HIV Status Affect Utilization of Maternal Care Services among Women in India: An Analysis of NFHS 2005-2006. World Journal of AIDS, 5, 105-112. http://dx.doi.org/10.4236/wja.2015.52013 
creasing the institutional deliveries and access to reproductive health care services including antenatal care [1]. In India, women who received at least three antenatal visits for their last pregnancy and medical assistance at delivery increased between 1992 and 2006, from 44\% to 51\% and from 35\% to 49\%, respectively [2]. The increase though small is attributed to the Janani Suraksha Yojna launched by the National Rural Health Mission, which promotes both antenatal care services and institutional deliveries [3].

In addition to regional, urban rural and income variations [4]-[6] in utilisation of maternal health care, individual factors such as age, religion, education level, caste [7] and health care level factors such as availability and accessibility of health care [8] affect the utilisation of health services. Among the individual factors, fertility, and parity of the mother are also considered as factors that determine the utilisation of the health facility [8]. While there are studies which illustrate on these in general population, few studies in India and elsewhere talk about the fertility and utilisation of health services among women by HIV status.

Studies from high HIV prevalent countries which have attempted to understand fertility behaviour among the HIV positive women do not conclusively say about the difference in terms of pregnancy intentions or desires by HIV serostatus [9], however few studies suggest a reduced desire [10] [11]. The decreased desire could be due to their apprehensions about their own health and upbringing of the child. Nevertheless, due to the importance and status a woman gets in the society in terms of her being pregnant or not pregnant, any differences in pregnancy cannot be attributed to the HIV status [12]. Recent studies also suggest that Anti Retroviral Therapy (ART) has increased opportunities and hopes for women wanting to be pregnant [13]. Few studies examine the relationship between HIV status and actual fertility [14] and this is majorly due to limitation in the availability of prospective data that can establish the relationship of HIV status on fertility [12]. A study in Vietnam suggests the positive association between awareness of HIV status and abortion [15], though giving the variation in cultural practices from place to place, the findings cannot be generalised. Few studies also suggest that women who are HIV positive seldom go to the health care provider due to reasons such as stigma and health care provider's negative attitude towards HIV positive women [16]. Contrary to this, studies examining the utilization of maternal health care services by HIV status illustrate an increasing utilisation of health care by the HIV positive compared to the negative [17] [18], majorly due to link of these services to the Ante Retroviral Treatment.

In India, though several studies have been carried out to understand the behavioural pattern including reproductive behaviour of the HIV infected population majorly among high-risk groups i.e., Female sex workers, Men having Sex with Men, Injecting Drug Users and long distance truck drivers who are clients of sex workers [19]-[22]. Nevertheless few studies in India look specifically into the utilisation of maternal health services or fertility and reproductive health by HIV status. This is majorly due to absence of specific data pertaining to this.

In India, though NACO estimates that about 0.8 million women are HIV positive, majority of them are unaware of their HIV status [23]. NACO has in-fact identified this as one of the major challenges in addressing the issues of prevention of HIV in India. Under the NACP-IV, this is targeted as one of the major issues and voluntary testing and treatment is being promoted vehemently (NACO).

In this paper, we examine the relationship between HIV status, ANC utilisation and fertility among women in India. The specific objectives of this paper are to analyze and study the differentials in some of the key maternal and child health related indicators among HIV-positive and HIV-negative women in India including: 1) fertility pattern, 2) ANC utilisation, 3) delivery and post-natal care seeking and 4) experience of miscarriages.

\section{Data and Methodology}

Data used for the study is taken from third round of the National Family Health Surveys conducted during the years 2005-2006 (NFHS-3). NFHS is a large scale, multi -rounded household survey designed to provide estimates of indicators of fertility, mortality, family planning, health, and nutrition of women aged 15 - 49 years at the national and state levels. In NFHS-3, biological parameters by blood tests for HIV and anaemia [2] were also collected. The necessary data required for this paper has been created by combining the HIV data records and the individual woman's data.

\subsection{Measures}

To measure fertility, selected indicators i.e., age at first intercourse, mean number of children ever born (CEB), pregnancy wastage/termination and total fertility rate (number of children born per woman) are considered. Total fertility rate is calculated from birth history information collected from all women aged 15 - 49 years. In or- 
der to examine the fertility among HIV positive and negative women, total fertility rate is calculated for births occurring during 5-year period preceding the survey and 10-year age grouping is prepared to have enough number of births included in the analysis to produce reliable fertility estimates, especially for the HIV-positive women. For understanding the utilisation of maternal health services, the following variables have been considered i.e., Ante natal Care, Assistance during delivery and Post natal check up.

\subsection{Statistical Analysis}

Cross tabulations and chi-square tests are used to examine the differentials in the utilisation of maternal health care services and experience of miscarriages among women according to their HIV status. The NFHS stratified random sampling needs weight to derive parameters estimates, so the HIV sample weights have been used in the analysis, however un-weighted numbers are provided for the HIV-positive cases. Odds ratios and 95\% confidence intervals were calculated.

\subsection{Sample Characteristics}

The NFHS-3, 2005-2006, collected information from 124, 385 women age 15 - 49 years and 74, 369 men age 15 54 years. Of these, blood samples were collected from a representative sub-sample of 52,853 women and 52,804 men. The numbers of cases reported in the tables are weighted and hence they may differ marginally from the un-weighted figures mentioned above.

We have examined the percent distribution of women age 15 - 49 years by HIV sample status and wealth index. It is evident that a lower proportion of women belonging to the poorest quintile were tested for HIV compared with those who are not tested (15 percent compared with 20 percent). However, a higher proportion of women from the middle and richer quintiles were tested for HIV compared with those not tested (45 percent vs. 37 percent). These differences are lower if we apply the HIV sample weights. It is of interest to note that, a higher proportion of women belonging to the middle and richer quintiles are HIV-positive compared with other quintiles. For example, one-third of all HIV-positive women are from the richer wealth quintile.

The distributions of all women age 15 - 49 years by marital status according to HIV sample status and HIVtest result indicated that of women interviewed, 21 percent were never married and 75 percent were currently married. The remaining four percent were widowed, divorced or not living together with a man as if married. There is no substantial difference noticed in the distribution between those tested for HIV and those not tested for HIV with respect to marital status. However, as expected, among those tested for HIV, the marital status distribution among HIV-negative and HIV-positive women differ substantially. For example, less than four percent of the HIV-positive women are never married compared with 20 percent among those who are HIV-negative. Similarly, among those women who are not living together with a man as if married, a much higher proportion is HIV-positive (6 percent vs. 1 percent).

\section{Results}

The differentials in fertility among HIV-positive and HIV-negative women were examined by the mean number of children ever born (CEB). The results of the mean number of children ever born, and mean and median age at first intercourse by HIV status are presented in Table 1. From the table it is evident that the mean CEB is substantially higher among HIV-negative women compared with HIV-positive women (2.8 among HIV-negative women compared with 2.1 among HIV-positive women). The mean and median age at first intercourse is lower among HIV-positive women (mean 16.9 years and median 16.0 years) compared with HIV-negative women (mean 17.2 years and median 17.0 years).

The current pregnancy status of women age 15 - 49 years according to the current HIV and marital status is shown in Table 1 . The proportion of women who are currently pregnant is substantially lower among HIV-positive women compared with HIV-negative women irrespective of their marital status. For example, among all women aged 15 - 49 years tested for HIV, more than five percent of the HIV-negative women are currently pregnant compared with less than three percent among those HIV-positive. The differences are even higher for ever married and currently married women. Similarly, the proportion of women who had a live birth during the 5-year period preceding the survey is also lower among HIV-positive women compared with HIV-negative women (see Table 1). Forty-two percent of the HIV-negative women currently married had at least one live birth during the 5-year period preceding the survey while the same proportion is only 20 percent among the HIV-positive women. 
Table 1. Characteristics of women age 15 - 49 years according to HIV-status, India, 2005-2006.

\begin{tabular}{|c|c|c|c|}
\hline & \multicolumn{2}{|c|}{ HIV Status } & \multirow{2}{*}{$\begin{array}{c}\text { All } \\
\text { Sample }\end{array}$} \\
\hline & Negative & Positive & \\
\hline Marital Status & $\%$ & $\%$ & $\%$ \\
\hline Never married & 20.4 & 3.5 & 20.3 \\
\hline Married & 74.8 & 66.1 & 74.8 \\
\hline Widowed & 3.2 & 22.6 & 3.3 \\
\hline Divorced & 0.3 & 1.7 & 0.3 \\
\hline Not living together & 1.3 & 6.1 & 1.3 \\
\hline Total & 100.0 & 100.0 & 100.0 \\
\hline No. of women & 53,216 & 115 & 53,331 \\
\hline \multicolumn{4}{|l|}{ Age at first intercourse (in years) } \\
\hline Mean & 17.2 & 16.9 & 17.2 \\
\hline Median & 17 & 16 & 17 \\
\hline Number of women ${ }^{*}$ & 41,156 & 108 & 41,265 \\
\hline Mean number of children ever born (CEB) & 2.83 & 2.08 & 2.83 \\
\hline Number of women* & 42,376 & 112 & 42,488 \\
\hline Pregnant at the time of survey (\%) & 5.3 & 2.6 & 5.3 \\
\hline Given birth during past 5 years & 31.9 & 19.8 & 31.9 \\
\hline All sample women & 53,217 & 115 & 53,332 \\
\hline Pregnant at the time of survey (\%) & 6.7 & 2.7 & 6.7 \\
\hline Given birth during past 5 years & 40.1 & 20.5 & 40 \\
\hline Ever married women & 42,376 & 111 & 42,487 \\
\hline Pregnant at the time of survey (\%) & 7.1 & 3.9 & 7.1 \\
\hline Given birth during past 5 years & 42.0 & 20.0 & 42.0 \\
\hline Currently married & 39,825 & 76 & 39,901 \\
\hline
\end{tabular}

*Number of women reported are different because of case elimination due to missing or inconsistent information on age at first intercourse.

Table 2 shows the TFR for the 5 -year period ${ }^{1}$ preceding the survey for women age 15 - 44 years computed for different sub-groups of women based on whether tested for HIV or not, and, among those tested, by their HIV status. Ten-year age specific fertility rates are calculated and presented in the table due to the small number of HIV-positive women in the sample. There is no noticeable difference in pattern of ASFR between HIV-positive and HIV-negative category of women though the rates were substantially lower for the HIV-positive category. The TFR among HIV-positive women (0.84) is substantially lower at one third of the TFR among HIV-negative women (2.78).

The proportion of HIV-positive pregnant women utilising ANC services is 92 percent compared to 78 percent among HIV-negative women, who had alive birth during the 5-year preceding the survey (Table 3). Seventy-nine percent of HIV-positive women have sought ANC services from a doctor compared to 50 percent among HIV-negative women. Similarly, the proportion of HIV-positive women delivering their babies in an institution is also much higher than among HIV-negative women (67 and 40 percent, respectively) (Table 3). The

${ }^{15}$-year period preceding the survey and 10-year age grouping are used to have enough number of births included in the analysis to produce reliable fertility estimates, especially for the HIV-positive women. 
Table 2. Total fertility rate (TFR) and age specific fertility rates for women age 15 - 44 years for the 5-year period preceding the survey by HIV-sample and HIV-status, India, 2005-2006.

\begin{tabular}{|c|c|c|c|c|c|c|}
\hline \multirow{3}{*}{ Age } & \multicolumn{3}{|c|}{ All women ${ }^{1}$} & \multicolumn{3}{|c|}{ HIV-sample women ${ }^{2}$} \\
\hline & HIV sample & Non-HIV sample & All & HIV-negative & HIV-positive & HIV Sample \\
\hline & \multicolumn{6}{|c|}{ Age Specific Fertility Rate (ASFR) } \\
\hline $15-24$ & 0.175 & 0.137 & 0.153 & 0.153 & 0.053 & 0.153 \\
\hline $25-34$ & 0.115 & 0.098 & 0.105 & 0.107 & 0.026 & 0.107 \\
\hline $35-44$ & 0.019 & 0.018 & 0.018 & 0.017 & 0.004 & 0.017 \\
\hline TFR & 3.09 & 2.52 & 2.77 & 2.78 & 0.84 & 2.77 \\
\hline
\end{tabular}

Note: 1 . The rates for "all women" are calculated using the "national all women weight" and for the "HIV-sample women" the "national HIV sample weight" is used. 2. 10-year age groups are used to get a better estimate for the HIV-positive sample.

Table 3. Pregnancy history, Delivery, ANC and PNC receiving among women age 15 - 49 years who had a live birth during past 5-years by HIV-status, India, 2005-2006.

\begin{tabular}{|c|c|c|c|}
\hline \multirow{2}{*}{ Percent of women experienced pregnancy wastage/termination } & \multicolumn{3}{|c|}{ HIV Status } \\
\hline & Negative & Positive & All \\
\hline Ever & 15.0 & 19.0 & 15.0 \\
\hline During 5-year preceding the survey & 5.9 & 8.7 & 5.9 \\
\hline Number of women & 53,215 & 116 & 53,331 \\
\hline Percent of institutional deliveries ${ }^{1}$ & 39.8 & 66.7 & 39.8 \\
\hline \multicolumn{4}{|l|}{ Assistance during delivery } \\
\hline Any health professional ${ }^{1}$ & 47.3 & 71.4 & 47.4 \\
\hline Doctor $^{1}$ & 36.1 & 63 & 36.1 \\
\hline ANM/nurse/midwife/LHV & 28.7 & 25 & 28.7 \\
\hline Other health professional & 1.4 & 3.6 & 1.4 \\
\hline $\mathrm{TBA}^{1}$ & 40.5 & 17.9 & 40.4 \\
\hline Relative/friend & 42.4 & 29.6 & 42.4 \\
\hline Other/none & 0.5 & 0.0 & 0.5 \\
\hline Number of births & 23,998 & $27^{* *}$ & 24,025 \\
\hline \multicolumn{4}{|l|}{ Antenatal care provider } \\
\hline Doctor $^{1}$ & 50.4 & 79.3 & 50.5 \\
\hline ANM/nurse/midwife/LHV & 36.5 & 43.9 & 36.5 \\
\hline Other health personnel & 1.7 & 0.0 & 1.7 \\
\hline Anganwadi/ICDS worker & 4.4 & 2.8 & 4.4 \\
\hline No antenatal care ${ }^{1}$ & 22 & 8.1 & 22 \\
\hline \multicolumn{4}{|l|}{ During pregnancy had: } \\
\hline Difficulty with daylight vision & 6.3 & 2.9 & 6.3 \\
\hline Difficulty with night blindness & 8.9 & 7 & 8.9 \\
\hline
\end{tabular}




\section{Continued}

Convulsions not from fever

Leg, body or face swelling ${ }^{1}$

Excessive fatigue $^{1}$

Vaginal bleeding

Received postnatal care

Less than 4 hours

4-23 hours

1 - 2 days

3 - 41 days

DK/missing

No postnatal care

Received with-in 42 days of delivery ${ }^{1}$

Number of women

\section{6}

26

49.3

4.8

27.6

4.9

5

4.1

1

57.3

41.6

16,994
4.2

47.1

63

2.7

26

49.3

4.9

5

4.1

1

57.3

41.7

$17,017^{\#}$

${ }^{* *}$ Un-weighted number is 49 ; ${ }^{1}$ Significantly different; Note: ${ }^{\#}$ The calculations refer to last live birth during past five years preceding the survey.

proportion assisted during delivery by a health professional is also higher among HIV-positive women compared with HIV-negative (71 percent among HIV-positive and 47 percent among HIV-negative).

The differential in the postnatal care coverage among HIV-negative and HIV-positive women is also substantial (42 percent and 61 percent, respectively). The differences are much higher for those receiving postnatal care within four hours of childbirth (Table 3).

The differentials in the complications during pregnancy indicate that prevalence of leg or body or face swelling and excessive fatigue is substantially higher among HIV-positive women compared with HIV-negative women (Table 3). For example, 47 percent of the HIV-positive women who had a live birth during 5-year period preceding the survey reported leg, body or face swelling compared with 26 percent among HIV-negative. However, no significant differences were observed with respect to other problems during pregnancy such as difficulty in daylight vision, night blindness, etc.

The experience of the pregnancy termination/miss-carriage among women according to the current HIV status was also analyzed and the results are presented in Table 3. The results suggest that a higher proportion of HIV-positive women experience pregnancy termination/miss-carriage than HIV-negative women.

\section{Discussion}

The results indicate that fertility among HIV-positive women is substantially lower than that of HIV-negative women. Though the TFR for the HIV-positive women is based on limited number of observations, a much lower TFR compared with HIV-negative women is indicative and conforms to earlier findings using population based data from Africa [24] [25]. Fertility is lower because of HIV infection or that women avoid pregnancy due to their HIV status. There is hardly any study carried out to understand the fertility pattern of HIV-positive and HIV-negative women in India or elsewhere using population based data, to further substantiate our claim.

Further, the antenatal care coverage, proportion delivering in an institutional facility and postnatal care among HIV-positive women are significantly higher than that of HIV-negative women. This highlights the fact that the chances of seeking antenatal care from a qualified health professional by HIV-positive women are higher than that of HIV-negative women [17]. This could be due to the linkages of ART services with the maternity care or due to the motivation and counselling offered to these women.

Similarly, a higher pregnancy termination among HIV positive women may either be due to HIV infection or due to women knowing their HIV status and hence terminating the pregnancy. This suggests the need to inves- 
tigate the relationship between HIV status and fertility further with new population based data sets to establish the linkages in detail.

NFHS-3 data does not provide the opportunity to explore this due to limited HIV-positive cases. The few HIV-positive cases in the sample restrict the scope of attempting multivariate analyses. Therefore, in this paper, the analysis is limited to cross tabulations at national level, though state-wise differentials in the HIV prevalence are substantial.

These limitations notwithstanding, the current study is among the first, to our knowledge, that uses NFHS data to understand fertility and ANC service utilisation by HIV status. While more work is needed for confirmation, findings suggest that HIV positive women are more likely to use the ANC services. Hence, the effort of the government to integrate ART services with Maternity care services is likely to have yielded benefits.

\section{Acknowledgements}

Thanks to Prof. RC Yadav for reviewing and providing comments that have improved this paper in a big way.

\section{References}

[1] United Nations (2014) The Millennium Development Goals. UN Millennium Development Goals Website. www.un.org/millenniumgoals

[2] International Institute for Population Sciences (IIPS) and Macro International (2007) National Family Health Survey (NFHS-3), 2005-06. IIPS, Mumbai.

[3] Government of India (2011). http://nrhm.gov.in/images/pdf/publication/Evaluation_study_of_NHM_in_7_States.pdf

[4] Montgomery, A.L., Ram, U., Kumar, R. and Jha, P., The Million Death Study Collaborators (2014) Maternal Mortality in India: Causes and Healthcare Service Use Based on a Nationally Representative Survey. PLoS ONE, 9, e83331. http://dx.doi.org/10.1371/journal.pone.0083331

[5] Singh, R.K. and Patra, S. (2013) Differentials in the Utilization of Antenatal Care Services in EAG States of India. International Research Journal of Social Sciences, 2, 28-32.

[6] Say, L. and Raine, R. (2007) A Systematic Review of Inequalities in the Use of Maternal Health Care in Developing Countries: Examining the Scale of the Problem and the Importance of Context. Bulletin of the World Health Organisation, 85, 733-820. http://dx.doi.org/10.2471/BLT.06.035659

[7] Navaneetham, K. and Dharmalingam, A. (2002) Utilization of Maternal Health Care Services in Southern India. Social Science \& Medicine, 55, 1849-1869. http://dx.doi.org/10.1016/S0277-9536(01)00313-6

[8] Singh, P.K., Kumar, C., Rai, R.K. and Singh, L. (2014) Factors Associated with Maternal Healthcare Services Utilization in Nine High Focus States in India: A Multilevel Analysis Based on 14385 Communities in 292 Districts. Health Policy Planning, 29, 542-559. http://dx.doi.org/10.1093/heapol/czt039

[9] Smee, N., Shetty, A.K., Stranix-Chibanda, L., Chirenje, M., Chipato, T., Maldonado, Y. and Portillo, C. (2011) Factors Associated with Repeat Pregnancy among Women in an Area of High HIV Prevalence in Zimbabwe. Women's Health Issues, 21, 222-229. http://dx.doi.org/10.1016/j.whi.2010.11.005

[10] Taulo, F., Berry, M., Tsui, A., Makanani, B., Kafulafula, G., Li, Q., Nkhoma, C., Kumwenda, J.J., Kumwenda, N. and Taha, E.T. (2009) Fertility Intentions of HIV-1 Infected and Uninfected Women in Malawi: A Longitudinal Study. AIDS and Behavior, 13, 20-27. http://dx.doi.org/10.1007/s10461-009-9547-9

[11] Yeatman, S.E. (2009) The Impact of HIV Status and Perceived Status on Fertility Desires in Rural Malawi. AIDS and Behaviour, 13, 12-19. http://dx.doi.org/10.1007/s10461-009-9534-1

[12] MacCarthy, S., Rasanathan, J.J., Ferguson, L. and Gruskin, S. (2012) The Pregnancy Decisions of HIV-Positive Women: The State of Knowledge and Way Forward. Reproductive Health Matters, 20, 119-140.

[13] Maier, M., Andia, I., Emenyonu, N., Guzman, D., Kaida, A., Pepper, L., Hogg, R. and Bangsberg, D.R. (2009) Antiretroviral Therapy Is Associated with Increased Fertility Desire, but Not Pregnancy or Live Birth, among HIV+ Women in an Early HIV Treatment Program in Rural Uganda. AIDS and Behaviour, 13, 28-37. http://dx.doi.org/10.1007/s10461-008-9371-7

[14] Magadi, M.A. and Agwanda, A.O. (2010) Investigating the Association between HIV/AIDS and Recent Fertility Patterns in Kenya. Social Science and Medicine, 71, 335-344.

[15] Chi, B.K., Hanh, N.T., Rasch, V. and Gammeltoft, T. (2010) Induced Abortion among HIV-Positive Women in Northern Vietnam: Exploring Reproductive Dilemmas. Culture, Health and Sexuality, 12, S41-S54. http://dx.doi.org/10.1080/13691050903056069

[16] Turan, J.M., Hatcher, A.H., Medema-Wijnveen, J., Onono, M., Miller, S., Bukusi, E.A., et al. (2012) The Role of 
HIV-Related Stigma in Utilization of Skilled Childbirth Services in Rural Kenya: A Prospective Mixed-Methods Study. PLoS Medicine, 9, e1001295. http://dx.doi.org/10.1371/journal.pmed.1001295

[17] Glynn, J.R., Buvé, A., Caraël, M., Musonda, R.M., Kahindo, M., Macauley, I., et al. (2001) Factors Influencing the Difference in HIV Prevalence between Antenatal Clinic and General Population in Sub-Saharan Africa. AIDS, 15, 1717-1725. http://dx.doi.org/10.1097/00002030-200109070-00016

[18] Sahlu, I., Howe, C.J., Clark, M.A. and Marshall, B.D.L. (2014) HIV Status, Knowledge of Mother-to-Child Transmission of HIV and Antenatal Care Use among Ethiopian Women. Journal of Epidemiology and Global Health, 4, $144-$ 184. http://dx.doi.org/10.1016/j.jegh.2014.01.001

[19] Becker, M.L., Ramesh, B.M., Washington, R.G., Halli, S., Blanchard, J.F. and Moses, S. (2007) Prevalence and Determinants of HIV Infection in South India: A Heterogeneous, Rural Epidemic. AIDS, 21, 739-747. http://dx.doi.org/10.1097/QAD.0b013e328012b885

[20] Ramesh, B.M., Moses, S., Washington, R., Isac, S., Mohapatra, B., Mahagaonkar, S.B., et al. (2008) Determinants of HIV Prevalence among Female Sex Workers in Four South Indian States: Analysis of Cross-Sectional Surveys in Twenty-Three Districts. AIDS, 22, S35-S44. http://dx.doi.org/10.1097/01.aids.0000343762.54831.5c

[21] Brahmam, G.N.V., Kodavalla, V., Rajkumar, H., Rachakulla, H.K., Kallam, S., Myakala, S.P., et al. (2008) Sexual Practices, HIV and Sexually Transmitted Infections among Self-Identified Men Who Have Sex with Men in Four High HIV Prevalence States of India. AIDS, 22, S45-S57. http://dx.doi.org/10.1097/01.aids.0000343763.54831.15

[22] Pandey, A., Benara, S.K., Roy, N., Sahu, D., Thomas, M., Joshi, D.K., et al. (2008) Risk Behaviour, Sexually Transmitted Infections and HIV among Long-Distance Truck Drivers: A Cross-Sectional Survey along National Highways in India. AIDS, 22, S81-S90. http://dx.doi.org/10.1097/01.aids.0000343766.00573.15

[23] National Institute of Medical Statistics (NIMS) and National AIDS Control Organisation (NACO) (2012) Technical Report India Estimates-2012.

[24] Kongnyuy, E.J. and Wiysonge, C.S. (2008) Association between Fertility and HIV Status: What Implications for HIV Estimates? BMC Public Health, 8, 309.

[25] Durevall, D. and Lindskog, A. (2008) Uncovering the Effect of the HIV Epidemic on Fertility in Sub-Saharan Africa: The Case of Malawi. Working Papers in Economics No 318, School of Business, Economics and Law, University of Gothenburg, Gothenburg. 